\title{
Determination of Informative Frequency Ranges for Buried Pipeline Location Control
}

\author{
Sergey A. Nazarychev ${ }^{1}$, Sergei O. Gaponenko ${ }^{2}$, Aleksandr E. Kondratiev ${ }^{3}$ \\ ${ }^{1}$ Kazan Federal University \\ ${ }^{2,3}$ Kazan State Power Engineering University \\ Email: nazarichev.sa@ gmail.com, Contact: 89376185067
}

\section{Received: 21st October 2017 Accepted: 16th November 2017, Published: 31st December 2017}

\begin{abstract}
ANSYS finite element analysis program was selected for calculations. This program obtained a high degree of verification. The method of theoretical research based on harmonic analysis has been determined.

The harmonic analysis is designed to solve the equations of motion in the case of steady-state oscillatory processes (forced oscillations). Three methods are available in order to carry out harmonic analysis in ANSYS system: complete, short and the method of mode superposition.

In order to solve the problem, the method of superposition of modes (MSM) was chosen, which uses natural frequencies and vibration modes to analyze the set forced harmonic oscillations.

The models of pipelines of various geometric sizes were built in ANSYS software package: 2000x40x6 (length $2000 \mathrm{~mm}$, diameter $40 \mathrm{~mm}$, pipe wall thickness $6 \mathrm{~mm}) ; \quad 5000 \times 40 \times 6 ; \quad 8000 \times 40 \times 6 ; \quad 2000 \times 75 \times 2$; $5000 \times 75 \times 2 ; \quad 8000 \times 75 \times 2 ; \quad 2000 \times 110 \times 2,2$ $5000 \times 110 \times 2,2 ; \quad 8000 \times 110 \times 2,2 ; \quad 2000 \times 125 \times 3,1$ $5000 \times 125 \times 3,1 ; \quad 8000 \times 125 \times 3,1 ; \quad 2000 \times 180 \times 4,4$; $5000 \times 180 \times 4,4 ; \quad 8000 \times 180 \times 4,4 ; \quad 2000 \times 250 \times 6,2$ $5000 \times 250 \times 6,2 ; \quad 8000 \times 250 \times 6,2 ; \quad 2000 \times 355 \times 8.7$ $5000 \mathrm{~h} 355 \mathrm{~h} 8.7 ; \quad 8000 \times 355 \times 8.7 ; \quad 2000 \times 630 \times 15.4$; $5000 \times 630 \times 15.4 ; \quad 8000 \times 630 \times 15.4 ; \quad 2000 \times 1000 \times 24,5$; $5000 \times 1000 \times 24,5 ; 8000 \times 1000 \times 24.5$ (GOST 185992001, GOST R 52134-2003, GOST 10705-91).

Calculations were carried out for all specified pipe sizes of three different materials: polypropylene, polyethylene and steel (St3).

Different depths of pipeline and the nature of soil were modeled by the change of pressure change on its outer shell.
\end{abstract}

Keywords: Pipeline, Harmonic Analysis, Forced Harmonic Oscillations, Mode Superposition Method, ANSYS.

\section{Introduction}

State policy in the field of environmental and industrial safety and new concepts of safety provision and accident-free production processes at economic facilities dictated by the Federal Law "On industrial safety of hazardous production facilities" No. 116-FL issued on 21.07.1997, the Federal law "On sanitary and epidemiological well-being of population" No. 170-FL issued on 30.03.1999, the Federal law "On

environmental protection" No. 7-FL issued on 10.01.2002 provide, first of all, an objective assessment of hazards and allow us to outline the ways of combat with them.

One of the most important areas of safety is the increase of energy efficiency and a reliable operation of various communications, which is provided by the development and the implementation of new more modern methods and the devices for their location monitoring.

The control of buried pipeline location is necessary for construction works, the laying of new communications or for well drilling since there is the question of manmade object exploitation safety increase. Safety is the prerequisite for any work on sites, and a damaged pipeline causes serious danger.

In the age of modern technologies, when a cable route or a pipeline can be shown using 3D modeling with GPS binding. Unfortunately, the issue of a hidden pipeline on a specific section of construction or other works or the absence of it remains extremely relevant. Engineering surveys, the laying of new communications with the digging of trenches and canals, the laying of hidden communications by the method of horizontally directed drilling (HDD) are often threatened with a breakdown or carried out with significant financial costs due to the absence of information or an accidental damage of power cable lines and pipelines. At that, the scope of tasks of contractors is not only limited to the performance of construction and repair works, but also to the provision of detailed information (plans, maps and diagrams) about the location of engineering networks. In order to avoid such situations, it is necessary to monitor the location of engineering communications [1-4].

\section{Methods}

The harmonic analysis procedure with the use of superposition mode method and the ACT expansion "Acoustic" consists of six basic steps:

1. Development of a geometric model.

2. The setting of material properties for a pipeline and an acoustic body inside it, the splitting of the model into the grid of finite elements.

3. Load specification and mounting conditions.

4. The performance of modal analysis, the obtaining of natural frequencies for a structure.

5. The creation of harmonic load on an acoustic body.

6. The conduct of harmonic analysis, the obtaining of amplitude-frequency characteristics for finite-element model oscillations. 
The pipeline models of various geometric sizes and materials were constructed in ANSYS software complex [5-10].

The different depth of a pipeline and the nature of soil were simulated by the change of pressure on its walls.

\section{Results}

1. The geometric dimensions of the pipeline under investigation are the following ones: 2000x40x6; 5000x40x6; 8000x40x6 (explanation, pipeline length $2000 \mathrm{~mm}$, diameter - $40 \mathrm{~mm}$, wall thickness $-6 \mathrm{~mm}$ ). The material is polypropylene; Poisson's ratio $\mathrm{v}=0,45$; the modulus of elasticity $\mathrm{E}=8.9 \times 10^{8} \mathrm{~N} / \mathrm{m}^{2}$; the density is $\mathrm{p}=946 \mathrm{~kg} / \mathrm{m}^{3}$ (Figure 1).

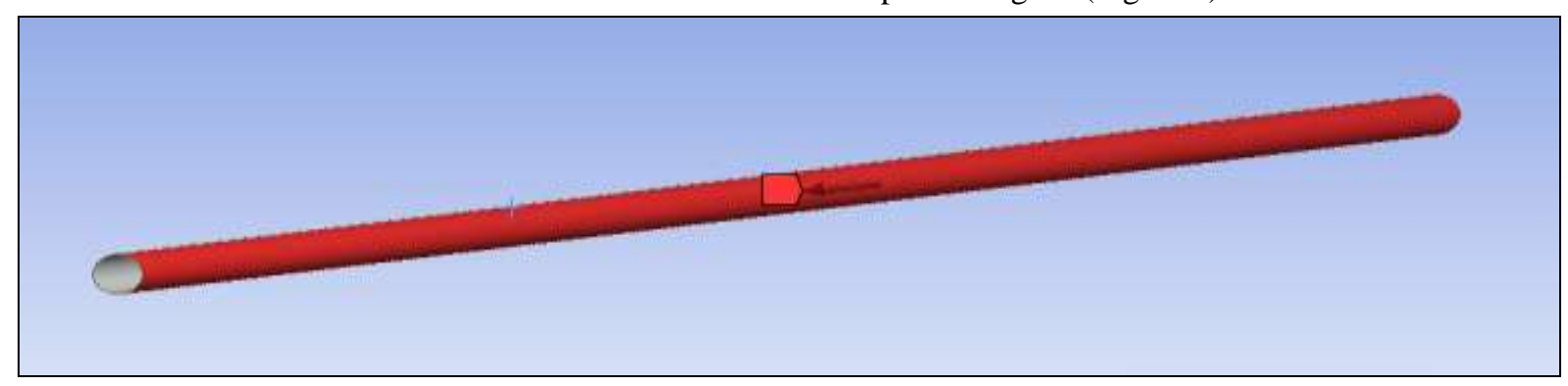

Fig. 1 Pipeline Model with Applied Pressure

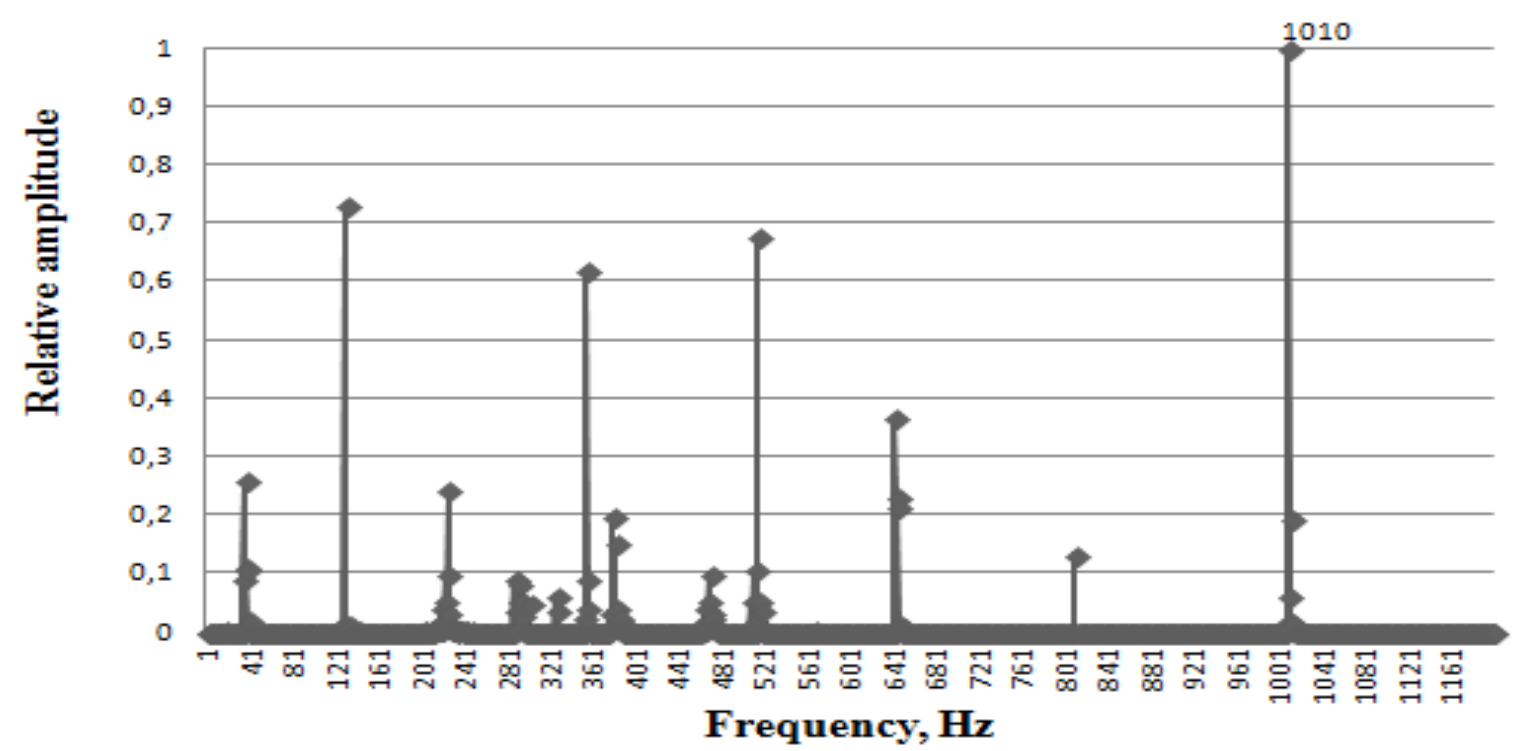

Fig. 2 The Result of Harmonic Analysis for the Pipeline 2000x40x6

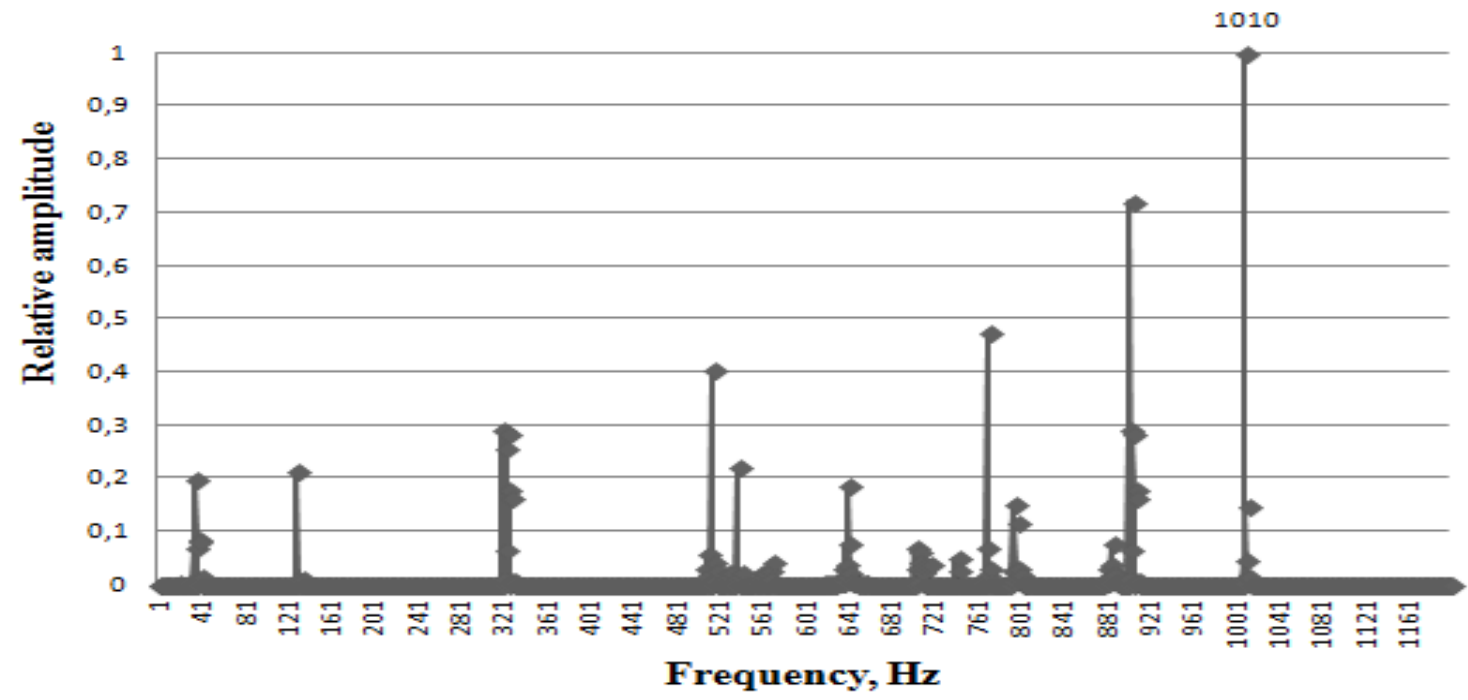

Fig. 3 The Result of Harmonic Analysis for the Pipeline 5000x40x6 


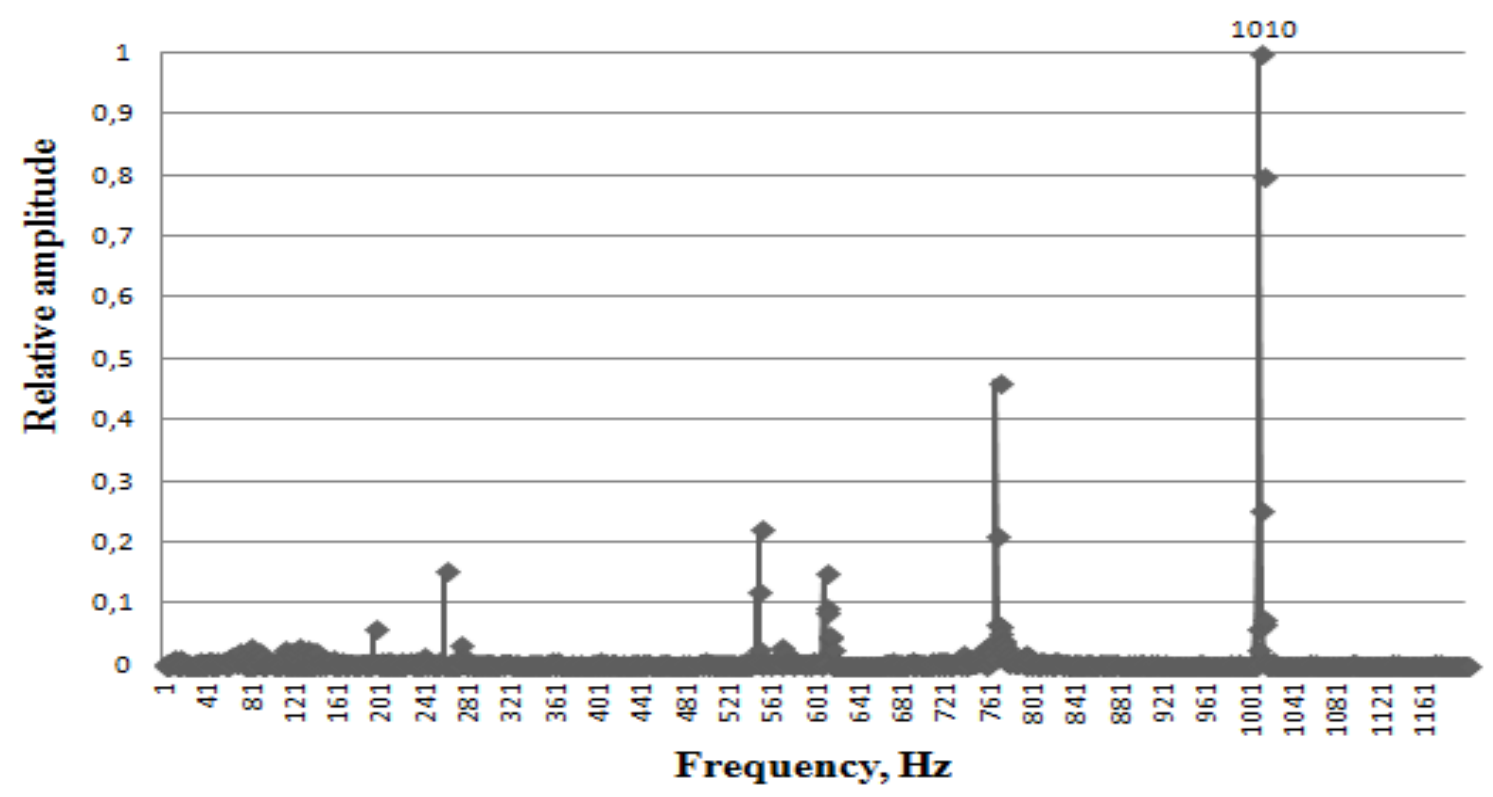

Fig. 4 The Result of Harmonic Analysis for the Pipeline 8000x40x6

It can be seen from these spectra that the informative frequency for the pipeline with the diameter of $40 \mathrm{~mm}$ and a wall thickness of $6 \mathrm{~mm}$ is $1010 \mathrm{~Hz}$.
A visual representation of the informative frequency was displayed at $1010 \mathrm{~Hz}$ in ANSYS software package (Fig. 5).
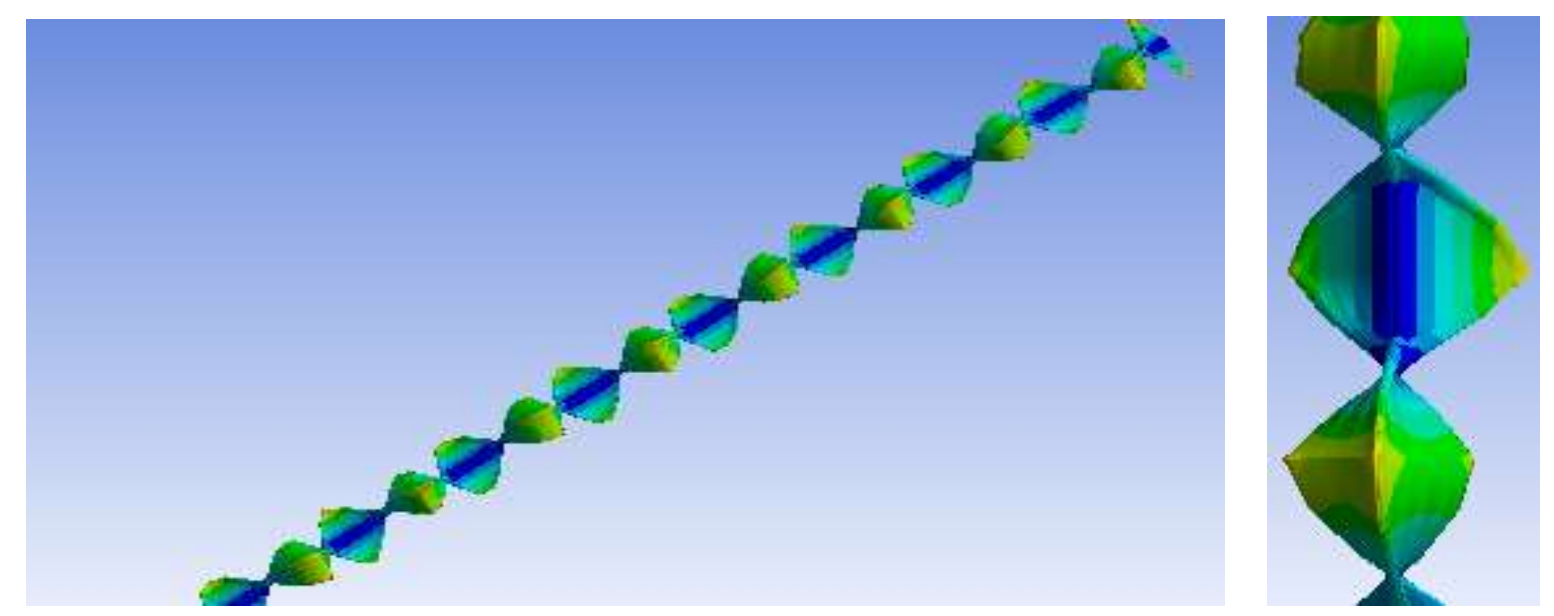

Fig. 5 The Shape of Oscillations for a Studied Pipeline at the Frequency of $1010 \mathrm{~Hz}$

The geometric dimensions of the pipeline under study are the following ones: $2000 \times 75 \times 2 ; 5000 \times 75 \times 2 ; 8000 \times 75 \times 2$. The material is polyethylene; Poisson's ratio $\mathrm{v}=$
0.42 ; the modulus of elasticity $\mathrm{E}=11 \times 10^{8}$ $\mathrm{N} / \mathrm{m}^{2}$; the density is $\mathrm{p}=950 \mathrm{~kg} / \mathrm{m}^{3}$.

The results of the harmonic analysis are shown on Fig. 6-8.

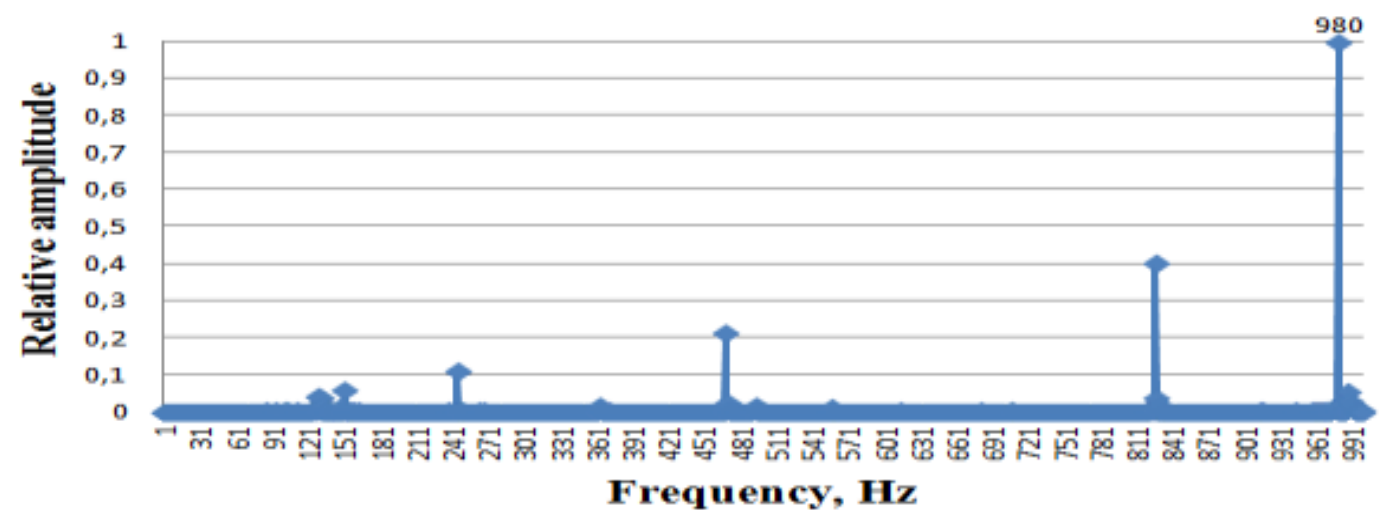


Fig. 6 The Result of Harmonic Analysis for the Pipeline 2000x75x2

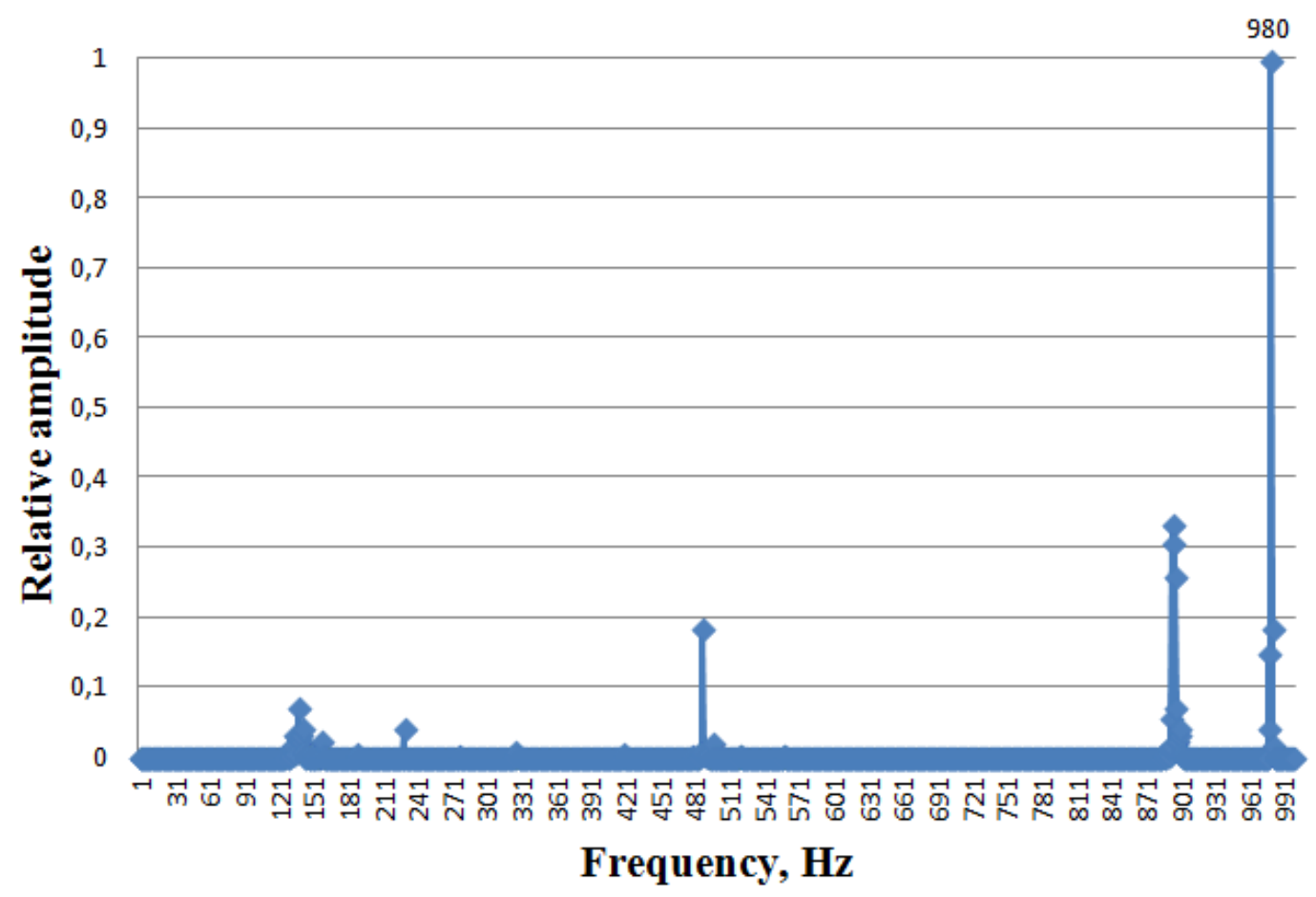

Fig. 7 The Result of Harmonic Analysis for the Pipeline 5000x75x2

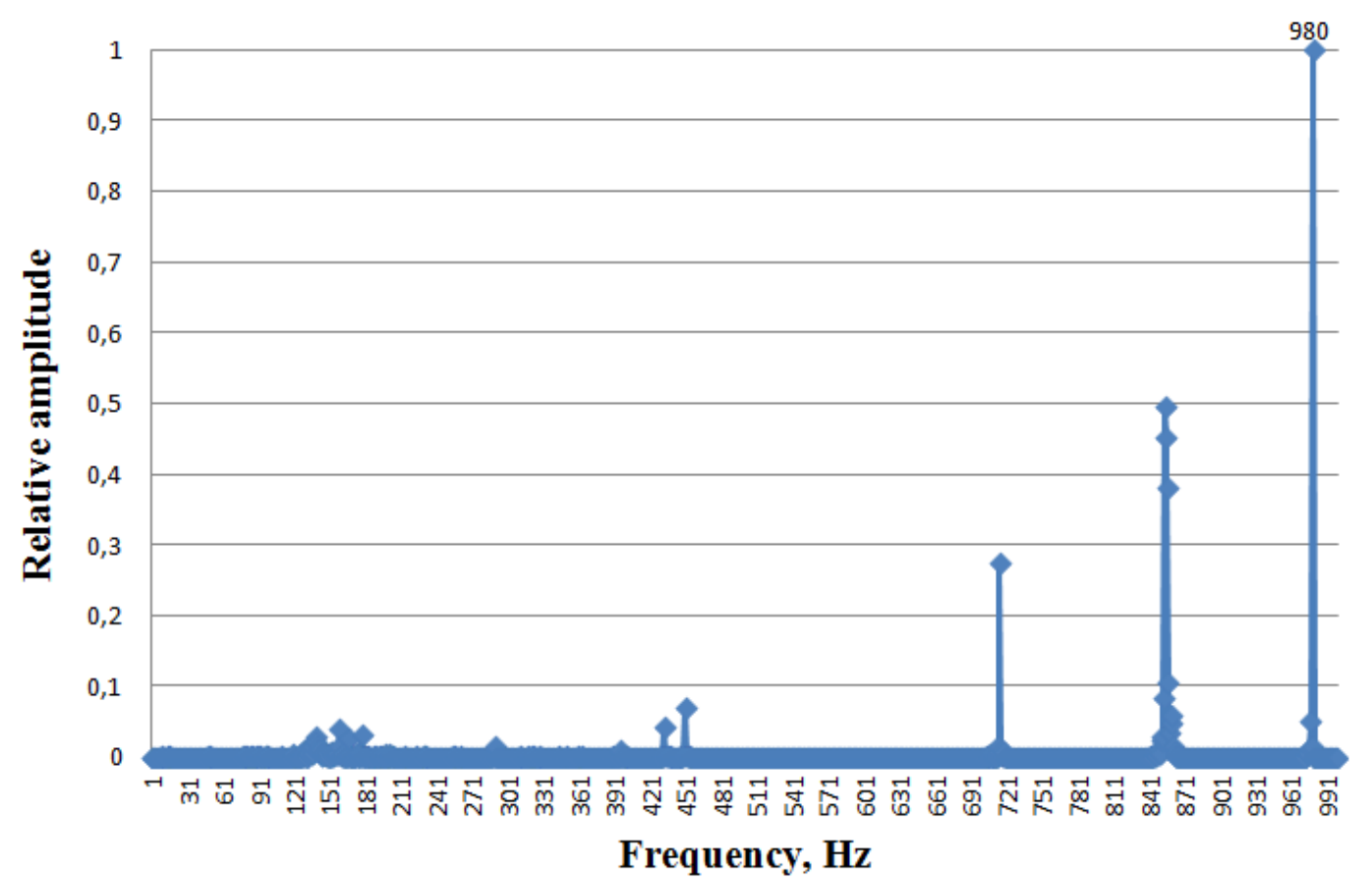

Fig. 8 The Result of Harmonic Analysis for the Pipeline 8000x75x2

It can be seen from these spectra that the informative frequency for the pipeline with the diameter of $75 \mathrm{~mm}$ and the wall thickness of $2 \mathrm{~mm}$ is $980 \mathrm{~Hz}$.

3. The geometric dimensions of the pipeline under

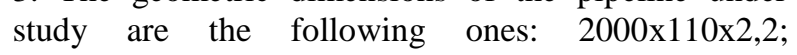

5000x110x2,2; 8000x110x2.2. Material: steel (St3); Poisson's ratio $\mathrm{v}=0,3$; modulus of elasticity $\mathrm{E}=$ $20 \times 10^{10} \mathrm{~N} / \mathrm{m}^{2}$; the density is $\mathrm{p}=7860 \mathrm{~kg} / \mathrm{m}^{3}$.

The results of the harmonic analysis are shown on Fig. 9-11. 


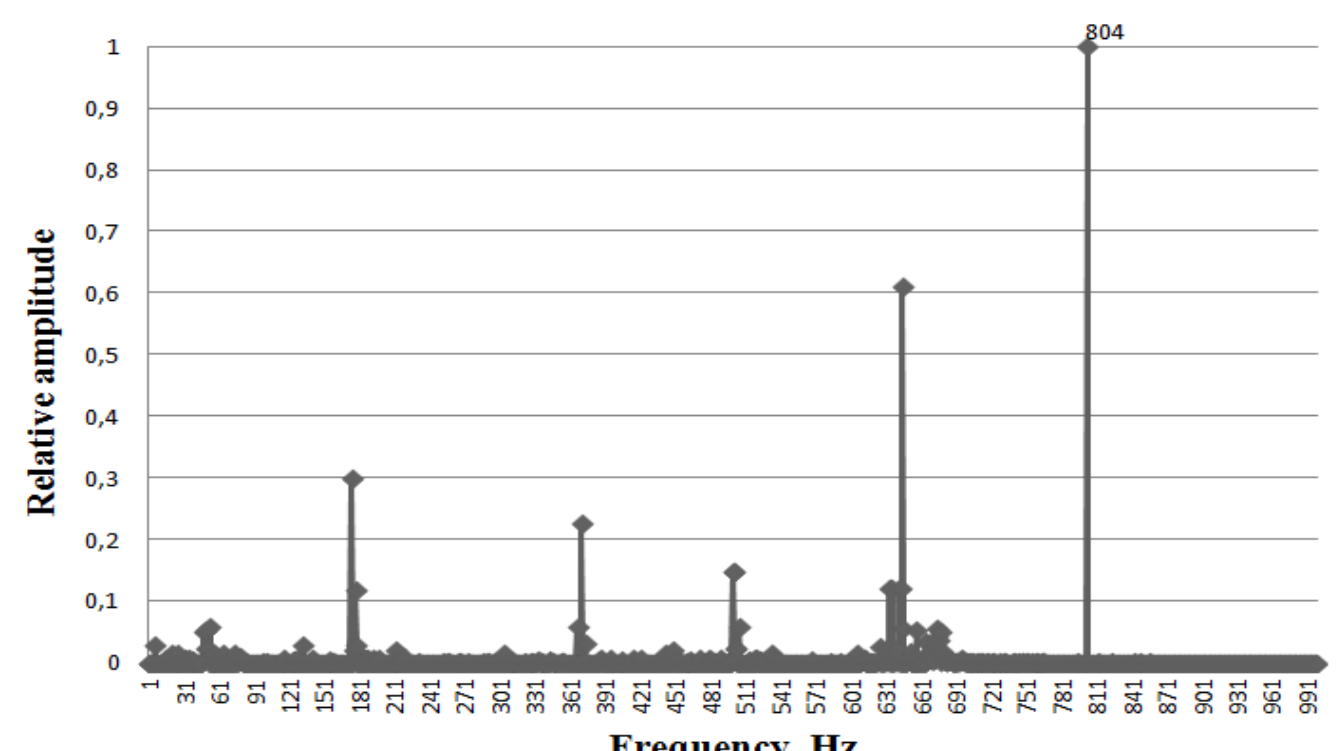

Fig. 9 The Result of Harmonic Analysis for the Pipeline 2000x110x2,2

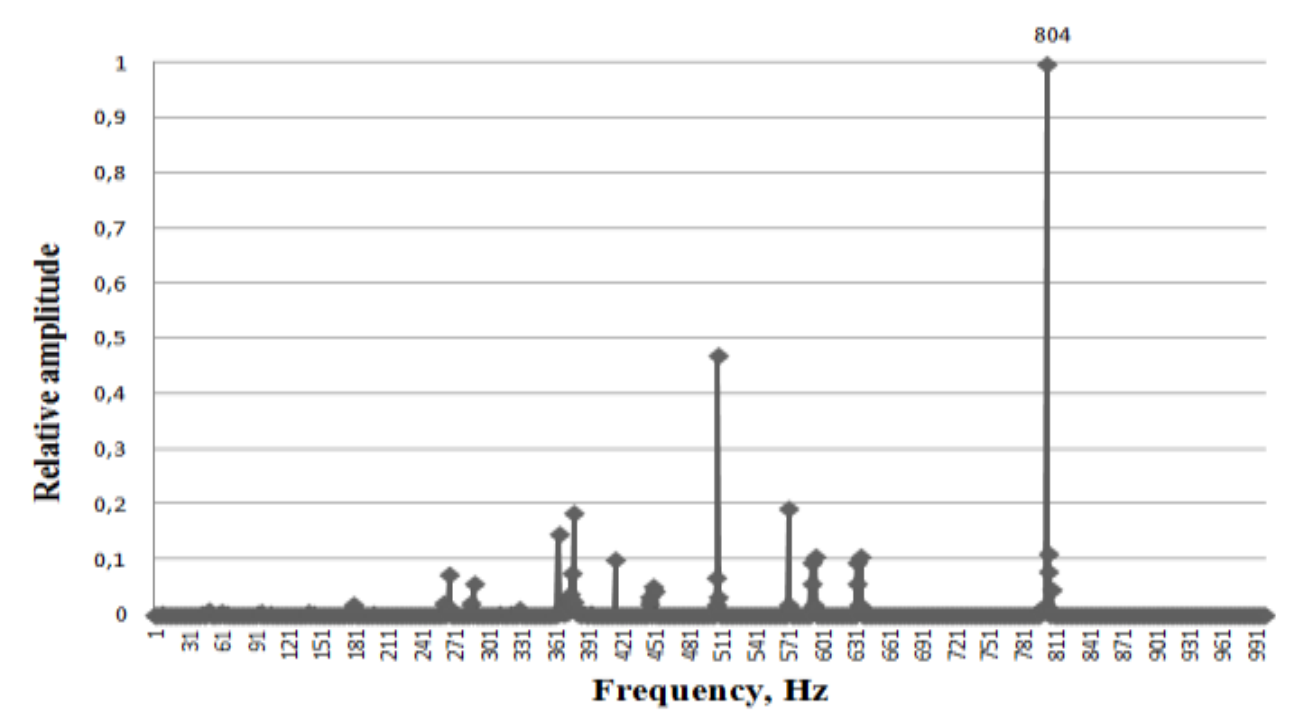

Fig. 10 The Result of Harmonic Analysis for the Pipeline 5000x110x2,2

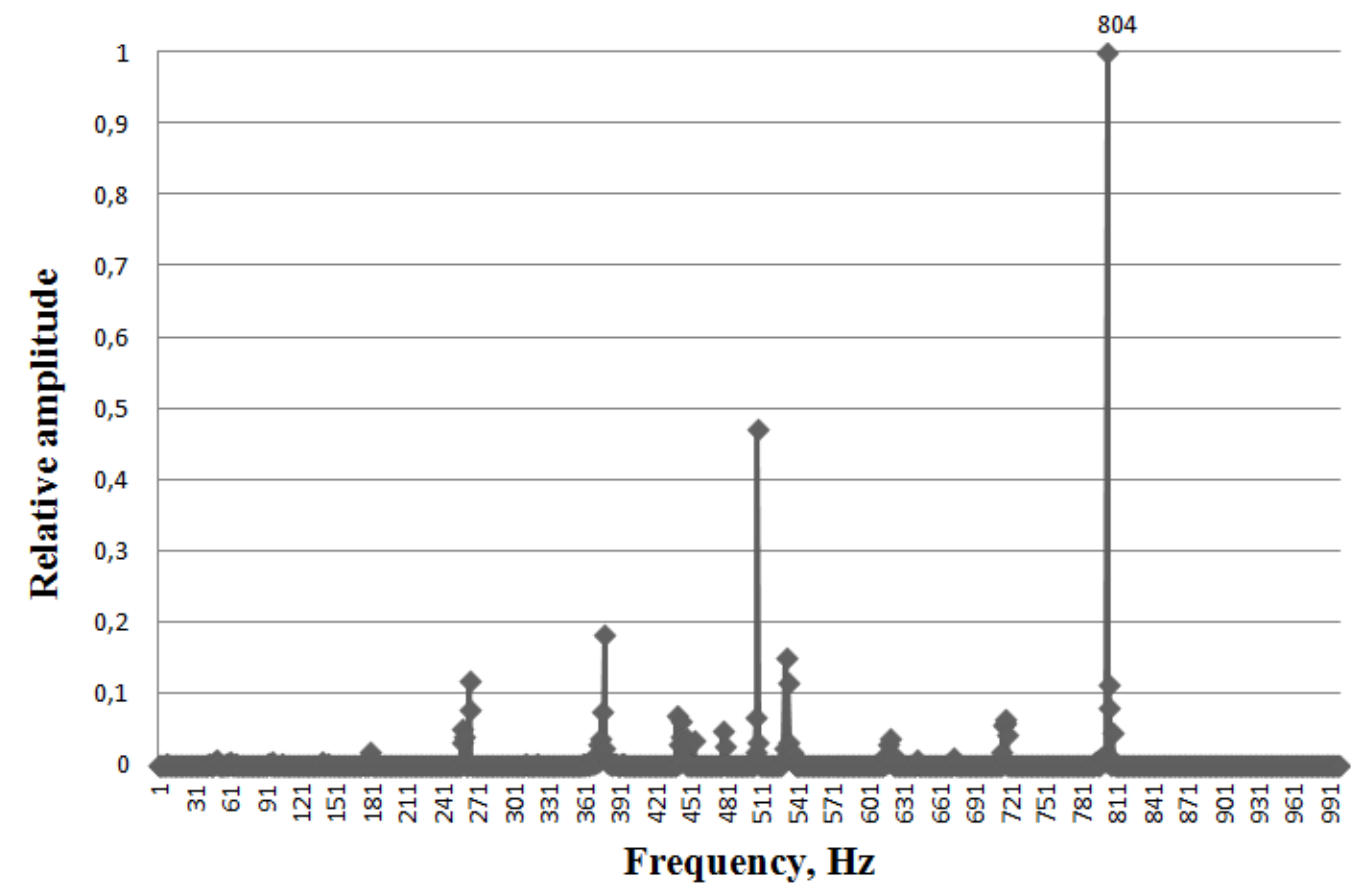


Fig. 11 The Result of Harmonic Analysis for the Pipeline 8000x110x2,2

These spectra demonstrate that the informative frequency for a pipeline with the diameter of $110 \mathrm{~mm}$ and a wall thickness of $2.2 \mathrm{~mm}$ is $804 \mathrm{~Hz}$.

\section{Discussion}

Figure 12 presents the informative frequency ranges to monitor the locations of simulated pipelines of different lengths, diameters and materials.

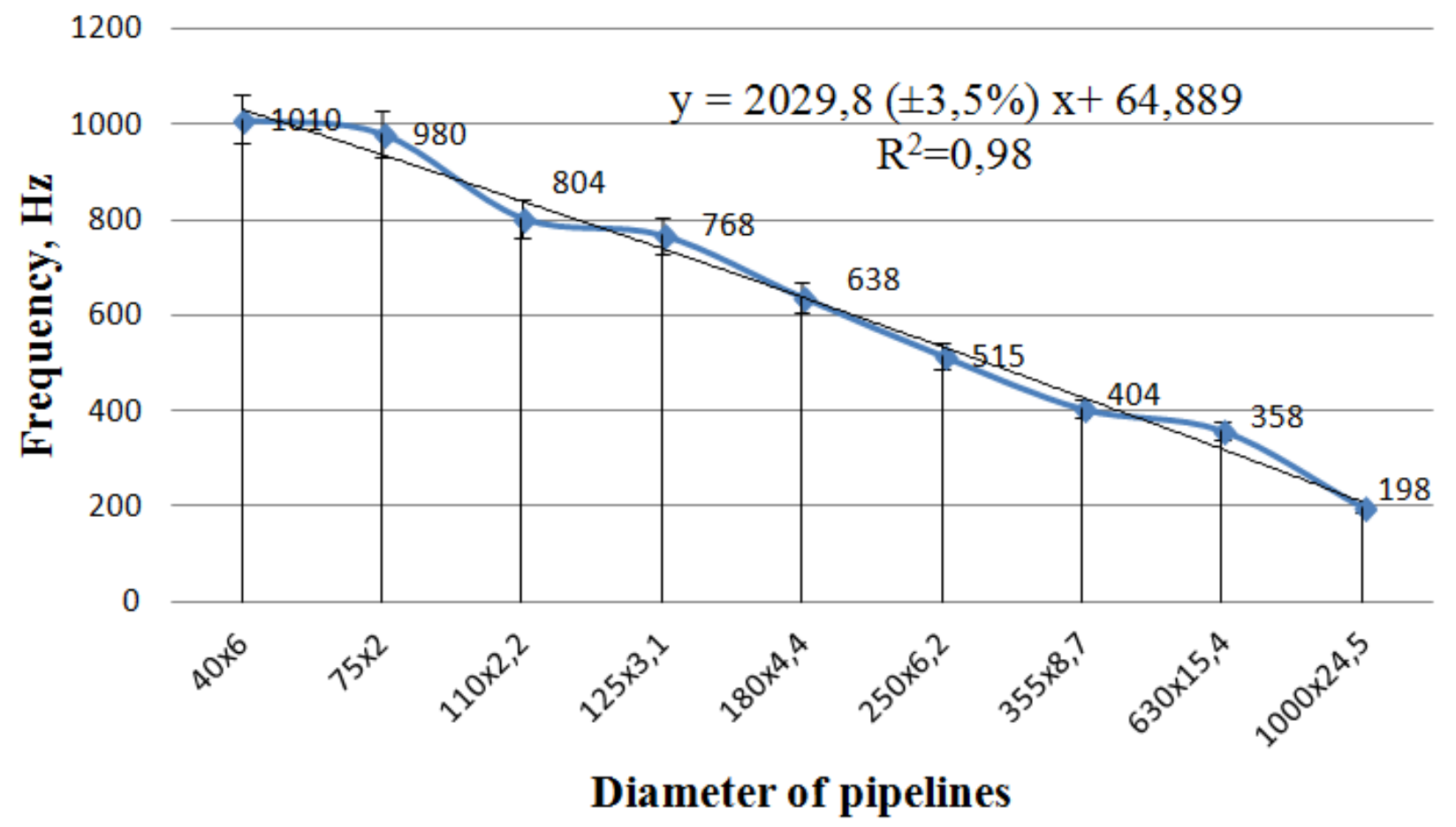

$\smile$ Frequency, $\mathrm{Hz}$

Fig. 12 Informative Frequency Ranges to Monitor the Location of Buried Pipelines

Based on carried out studies, it is assumed that a standing wave is excited in a pipeline.

\section{Conclusions}

The conducted researches allowed to draw the following conclusions:

1. Informative frequency ranges of buried pipeline location monitoring have been determined. The pipelines are made of various materials.

2. Different soil types, depths, materials and lengths of the pipelines under study do not affect the selected resonance frequencies of oscillations.

3. The selected resonant frequencies are practically linearly dependent on the diameter of the pipeline under study.

4. The most informative frequency range is $100-1100$ $\mathrm{Hz}$, in which the selected resonant frequencies of simulated pipelines are located (Fig. 12).
Consequently, the fundamental resonance frequency depends on a pipeline diameter.

\section{Summary}

Based on the studies, they developed the mathematical model of an object control for recessed polypropylene, polyethylene and steel pipelines at various depths with the diameter of $40-1000 \mathrm{~mm}$ using the finite element method to determine informative frequency ranges.

\section{Acknowledgements}

The work is performed according to the Russian Government Program of Competitive Growth of Kazan Federal University.

\section{References}

[1] Pat. 2482515 Rus. Federation: IPC G01V1 / 00, G01N29 / 00. Pipeline location determination method / A.E. Kondratiev, S.O. Gaponenko; 
Applicant and patent holder: FSBEI HPE "KGEU" (RU). - No. 2011151380/28; appl. 12/15/2011; publ. on 05/20/2013; bul. №14. - 6 p.

[2] S.O. Gaponenko, A.E. Kondratiev, "Model unit for the development of the method determining the location of hidden pipelines", University bulletin. Problems of energy, № 7-8, pp. 123129, 2014.

[3] S.O. Gaponenko, A.E. Kondratiev, "Perspective methods and techniques for hidden channels, cavities and pipelines searching with a vibration-acoustic method", Bulletin of the North-Caucasian Federal University, No. 2 (47), pp. 9-13, 2015.

[4] S.O. Gaponenko, A.E. Kondratiev, A.R. Zagretdinov, "Low-frequency vibration-acoustic method of determination of the location of the hidden canals and pipelines", Procedia Engineering, vol. 150, pp. 2321-2326, 2016.

[5] N.V. Leontyev. "Application of ANSYS system to solve the problems of modal and harmonic analysis". N. Novgorod: Nizhny Novgorod State University named after N.I. Lobachevsky, 2006, $102 \mathrm{p}$.

[6] K.A. Basov, "ANSYS in examples and tasks", Moscow, Computer Press, 2002, 224 p.

[7] L. Segerlind, "The application of the finite element method", Moscow, 1979, 392 p.

[8] R. Galagher. "The finite element method. Fundamentals", Moscow, Mir, 1984, 428 p.

[9] A.R.D. Curtis, P.A. Nelson, S.J. Elliott, A.J. Bullmore, "Active suppression of acoustic resonance", J. Acoust. Soc. Am., vol. 81, № 3, pp. 624-631, 1987.

[10] C.L. Dym, B.S. Ivey, "Principles of Mathematical Modelling", New York: Academic Press, 1980, 256 p. 